\title{
BMJ Open Drugs causing adverse events in patients aged 45 or older: a randomised survey of Australian general practice patients
}

\author{
Graeme C Miller, Lisa Valenti, Helena Britt, Clare Bayram
}

To cite: Miller GC, Valenti L, Britt $\mathrm{H}$, et al. Drugs causing adverse events in patients aged 45 or older: a randomised survey of Australian general practice patients. BMJ Open 2013;3: e003701. doi:10.1136/ bmjopen-2013-003701

- Prepublication history and additional material for this paper is available online. To view these files please visit the journal online (http://dx.doi.org/10.1136/ bmjopen-2013-003701)

Received 1 August 2013 Revised 12 September 2013 Accepted 13 September 2013

Family Medicine Research Centre, School of Public Health, University of Sydney, Sydney, Australia

\section{Correspondence to} Dr Graeme C Miller: graeme.miller@sydney.edu.au

\section{ABSTRACT}

Objective: To determine prevalence of adverse drug events (ADEs) in patients aged 45 years or older presenting to Australian general practitioners (GPs) and identify drug groups related to ADEs, their severity and manifestation.

Design: Substudy of the Bettering the Evaluation and Care of Health continuous survey of Australian GP clinical activity in which randomly selected GPs collected survey data from patients. Data are reported with $95 \%$ Cls.

Setting: General practice in Australia.

Main outcome measures: Prevalence in the preceding 6 months, type, implicated drugs, severity (including hospitalisation) and manifestation of ADEs. Participants: From three survey samples, JanuaryOctober 2007, and two samples, January-March 2010, responses were received from 482 GPs about 7561 patients aged 45 years or older.

Results: Of a final sample of 7518 patients (after duplicate patients removed), 871 (11.6\%) reported ADEs in the previous 6 months. The type of ADE was recognised side effect $(75.8 \%, 95 \% \mathrm{Cl} 72.0$ to 79.7$)$, drug sensitivity $(9.9 \%, 95 \% \mathrm{Cl} 7.2$ to 12.7$)$ and drug allergy $(7.4 \%, 95 \% \mathrm{Cl} 4.7$ to 10.1$)$. Drug interaction $(1.0 \%, 95 \% \mathrm{Cl} 0.1$ to 1.8$)$, overdose $(0.8 \%, 95 \% \mathrm{Cl} 0.0$ to 1.5$)$ and contraindications $(0.2 \%, 95 \% \mathrm{Cl} 0.0$ to 0.6$)$ were very infrequent. A severity rating was provided for 846 patients. Almost half $(45.9 \%, 95 \% \mathrm{Cl} 42.0$ to 49.7$)$ were rated as 'mild' events, $42.2 \%(95 \% \mathrm{Cl} 38.8$ to 45.6) 'moderate', $11.8 \%$ (95\% Cl 9.5 to 14.1 ) severe and $5.4 \%(95 \% \mathrm{Cl} 3.8$ to 7.0$)$ had been hospitalised as a result of the most recent $A D E$. Thirteen commonly prescribed drug groups accounted for $58 \%$ of all ADEs, opioids being the group most often implicated.

Conclusion: ADEs in patients aged 45 or older are frequent and are associated with significant morbidity. Most of ADEs result from commonly prescribed drugs at therapeutic dosage. The list of causative agents bears little relationship to published lists of 'inappropriate medications'.

\section{INTRODUCTION}

The Australian healthcare system is similar in many ways to most others in the Organisation for Economic Co-operation and Development

\section{ARTICLE SUMMARY}

Strengths and limitations of this study

- A major strength of this study is that it contains data from 7518 patients collected by hundreds of randomly selected general practitioners (GPs) representing $2.7 \%$ of all practicing GPS in Australia.

- Older patients with multiple morbidity and polypharmacy present more frequently to GPS and this results in a selection bias in the study.

- The study used patient recall of events in the preceding 6 months, which may lead to underreporting due to recall bias.

(OECD) group of nations. In 2011, Australia had a population of 22.5 million people, cared for by 22500 primary medical care practitioners who are the gate keepers to the secondary and tertiary health sectors. There is a universal medical insurance scheme (Medicare) administered by the Australian Government. Primary medical care is provided on a fee-for-service basis without patient enrolment lists. In 2011, there were about 120 million claims for primary medical care services per year at an average of five services per head of population. ${ }^{1}$

In common with other OECD countries, Australia has an ageing population with a resulting increase in the prevalence of multimorbidity ${ }^{2}$ and polypharmacy. Polypharmacy in older patients is accompanied by a high level of adverse drug events (ADEs). ${ }^{4-7}$ Miller et al found that $15 \%$ of patients aged 65 years and older in Australia reported an ADE in the 6 months prior to their surveyed attendance at a primary medical care encounter. The significant morbidity from ADEs in older patients has been widely reported in the literature. ${ }^{6} 79$

Worldwide concern regarding ADEs in older patients has led to attempts to identify 'inappropriate medications' (IMs) that may be causing ADEs in order to guide prescribing and reduce patient risk. In 1991, Beers et al ${ }^{10}$ defined explicit criteria for determining 
inappropriate medication use in the elderly using a consensus (Delphi) process. The Beers list was revised in $1997^{11}$ and by Fick et $a l^{12}$ in 2003.

Laroche et al reviewed the correlation between the use of IMs as defined by Beers et al and others and the occurrence of ADEs in multiple studies and concluded that 'more than the inappropriateness of the drugs themselves, it is the inappropriate use of drugs that is to be tackled when treating the elderly'. Laroche et al also suggested that the reduction in the number of drugs given is the major factor in the prevention of ADEs. However, little data are available on which drugs used by older patients in community practice are significantly associated with ADEs and are thus the drugs to be considered in any recommendations to reduce use.

The aim of this study was to identify the drug groups related to the occurrence and severity of ADEs in community patients aged 45 and older and the manifestations of these ADEs.

\section{METHODS}

\section{Collection methods and sample}

This study was conducted through the Bettering the Evaluation and Care of Health (BEACH) program. BEACH is a continuous, national, cross-sectional survey of Australian general practice activity. The BEACH methods are described in detail elsewhere, ${ }^{13}$ but in summary, general practitioners (GPs) from everchanging random samples of the (approximately) 18000 currently practising recognised GPs in Australia are invited to participate. Annually, 1250 GPs are recruited and posted survey packs, from which approximately 1000 completed surveys are returned. Each GP records details for 100 consecutive encounters with consenting, unidentified patients, on structured paper forms. Information is collected about the problems managed and how they are managed, for each patient at the single visit on the day the GP is participating. ${ }^{13}$

Because the survey is cross-sectional, patients may have health problems that were not managed at the recorded visit. To investigate these aspects of the patient health, a series of substudies are conducted in conjunction with the ongoing data collection from the GP-patient encounters. In each 5 week collection period about 100 GPs each records information for approximately 30 consecutive patients for each topic, a completed sample of about 3000 patients per substudy. ${ }^{14}$ These substudies, known as Supplementary Analysis of Nominated Data (SAND), investigate aspects of the patient health not necessarily managed at the encounter (full methods reported elsewhere).$^{15}$ Responses are recorded by the GP, about the patient, in discussion with the patient. Using a qualified medical practitioner to record morbidity in conjunction with the patient self-report may provide a more accurate classification of patients' health problems than the self-report alone. ${ }^{16}{ }^{17}$ A total of five SAND subsamples were used: three data collection periods were between January and October 2007; and two between January and March 2010. These data were used to investigate the frequency, cause, reaction type (recognised side effect, drug interaction, contraindication, allergy, drug sensitivity, overdose or other) and severity of ADEs reported by patients to have occurred within the previous 6 months.

\section{Adverse drug events}

For the purpose of this study, an ADE is defined as an 'unintended event, due to the use of a medication that could have harmed or did harm the patient'. 'Harm' includes physical, psychological or emotional suffering. This definition is consistent with the definition of the broader concept of 'clinical incidents' used in our seminal work on the patient safety incidents in general practice in Australia. ${ }^{18}$

\section{Data collected}

The number of questions that could be asked about the patient was limited by the space available on the recording form. Each GP was asked to record whether or not each of the 30 patients had experienced an ADE in the preceding 6 months. If the response was 'no' the questions ended. Where a 'yes' response was recorded, the GP was then asked to report on the medication or medications involved in the most recent event. The GP was then asked to record the type of adverse event. Nine options with tick boxes were offered for recording the type of the event: a recognised side effect, drug interaction, contraindication, allergy, drug sensitivity, overdose, dispensing error, don't know and other. Type was not recorded in the last two collection periods. Severity was recorded as one of four options (mild, moderate, severe and don't know). Hospitalisation was recorded for all patients with ADEs. GPs were asked to use their clinical judgement in assessing the severity of the ADE but guiding definitions were provided (box 1 ).

In the two collection periods in 2010 the GPs were also asked to record the symptoms and signs resulting from the $\mathrm{ADE}$, and their duration.

There were no statistical differences in the age and sex distributions of respondents between the collection periods and between the collections and the whole BEACH collection during the same period (results not tabled). For subsequent analysis of ADE prevalence,

\section{Box 1 Definition provided to participating general} practitioners

Severity of the event

- Mild: a reaction of limited duration which may or may not require further treatment; minimum impact on daily activities

- Moderate: a reaction of longer duration or which requires further treatment; limits daily activities.

- Severe: a reaction of any duration which results in hospitalisations and or long-term limitations of daily activities. 
causative drug, severity and hospitalisation, all five samples were amalgamated into a single sample.

As the age group of interest for this paper was older Australians, who have significantly higher rates of ADEs than younger Australians, ${ }^{8}$ and as there was no statistical difference between the $\mathrm{ADE}$ rates for all age groups 45 years and above (figure 1 ), patients in these age groups were amalgamated for analysis.

\section{Classification of data}

Drugs reported as implicated in the cause of ADEs were classified using the WHO's Anatomical Therapeutic Chemical (ATC) classification. ${ }^{19}$ Manifestations of the ADEs were classified according to the International Classification of Primary Care V.2 (ICPC-2).$^{20}$

\section{Comparison of rates of prescribing and ADEs}

We compared prescribing rates (drug group as a proportion of all drugs prescribed) derived from BEACH data for the years 2007-10, with ADE rates (drug group as a proportion of all ADEs) for groups of drugs at ATC classification level 3. If each drug group had an equal likelihood of producing ADEs, the rate of ADEs produced by a drug group should be similar to the rate of prescribing. We used non-overlapping CIs as a conservative measure of the likelihood that one drug group was more or less likely to result in ADEs than another.

\section{Statistical analysis}

A cluster sample design was used with the GP being the primary sampling unit, and the patient at the encounter the unit of analysis. Procedures in SAS V.9.1 ${ }^{21}$ accounting for the cluster study design were used to determine robust $95 \%$ CIs for the resulting estimates and percentages. Significance of differences was judged by nonoverlapping CIs. Where responses were not provided, missing data were removed from the analyses.

An unadjusted prevalence estimate was calculated as the number of patients with at least one ADE as a proportion of the total sample of respondents. This estimate can be interpreted as the prevalence of ADEs among patients who present to GPs.

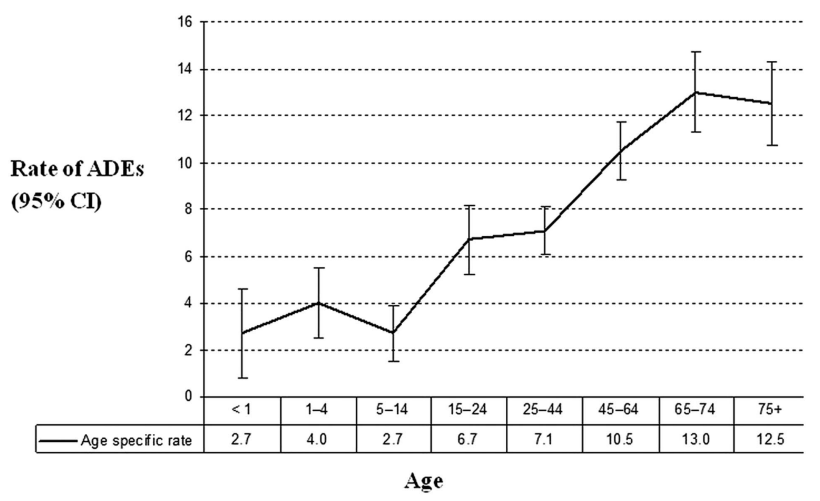

Figure 1 Age-specific rate of adverse drug events (ADE).

\section{RESULTS}

\section{Response rates}

The responses received on 7561 encounter forms from patients aged 45 years or over, were provided by 482 GPs. Of these, 35 were excluded, (duplicate patients on the basis of matching demographic data), leaving a final sample of 7518 patients. The age and sex distributions of the respondents did not differ from those of patients in the total sample of BEACH encounters for 2006$2010 .^{22}$

\section{Rates of ADEs}

The GPs reported that 871 patients aged 45 or older (11.6\%) had experienced an adverse event in response to using a medication in the previous 6 months. This result was consistent over the five recording periods (table 1). All other results from questions repeated in the five recording blocks did not significantly differ and are reported here in consolidated form.

Our previously published research demonstrated that the likelihood of an ADE increased with age to peak in those aged 45-64 years and remained at the same level in those in older age groups. ${ }^{8}$ This distribution of ADEs with age was confirmed in this study (figure 1). Women (12.9\%, $95 \%$ CI 11.6 to 14.2$)$ were significantly more likely than male patients $(9.5 \%, 95 \%$ CI 8.3 to 10.7$)$ to have experienced an $\mathrm{ADE}$.

For the vast majority $(91.7 \%)$ of 842 respondents only one drug was said to be implicated in the most recent ADE, but in $8.3 \%$ two drugs were implicated.

\section{Type of ADEs}

Type of the ADEs was investigated in the first three collection periods. Of the 533 patients in these collection periods, GPs reported type of ADEs for 525 patients. The GPs assessment of the type of the ADE was: recognised side effect for $75.8 \%(95 \%$ CI 72.0 to 79.7$)$ of occurrences, drug sensitivity for $9.9 \%$ (95\% CI 7.2 to 12.7) and drug allergy for $7.4 \%$ (95\% CI 4.7 to 10.1). Prescribing errors such as drug interaction $(1.0 \%, 95 \%$ CI 0.1 to 1.8$)$, overdose $(0.8 \%, 95 \%$ CI 0.0 to 1.5$)$ and contraindications $(0.2 \%, 95 \%$ CI 0.0 to 0.6$)$ were very infrequent.

\section{Severity of ADEs}

A GP severity rating for the most recent $\mathrm{ADE}$ was provided for 846 patients. Almost half (45.9\%, 95\% CI 42.0 to 49.7) were rated as having a 'mild' event(s), with $42.2 \%$ (95\% CI 38.8 to 45.6$)$ rated as 'moderate'. A 'severe' rating was given for 100 patients, $11.8 \%$ (95\% CI 9.5 to 14.1 ) of those with an ADE for whom a response to this question was received.

\section{Hospitalisation for ADEs}

Responses to the question on hospitalisation were received for 831 patients, of whom $5.4 \%$ (95\% CI 3.8 to 7.0) had been hospitalised as a result of the most recent $\mathrm{ADE}$. Hospitalisation rates were highest in those 


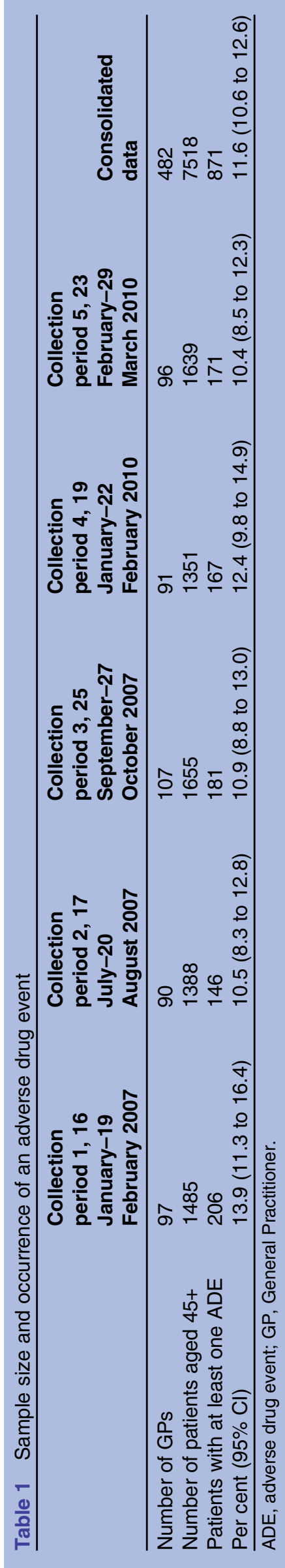

patients whose $\mathrm{ADE}$ was rated as severe $(31.6 \%, 95 \%$ CI $22.3-$ to 1.0$)$.

\section{Medications associated with ADEs}

Table 2 shows the 13 drug groups (ATC level 3) most frequently implicated in ADEs in this study in ADE frequency order. Together these drug groups accounted for $58.6 \%$ of all reported ADEs. The relative prescribing frequency and relative $\mathrm{ADE}$ frequency for each group are also provided. Also shown are the most commonly implicated drug subgroups (at ATC level 4 or at level 3 in some instances where the whole group is implicated) with the distribution of grades of severity of ADEs and frequency of hospitalisation. The last column shows the most common manifestations of the ADEs for each drug subgroup.

Opioids were the most frequently implicated drugs, accounting for $8.2 \%$ of all ADEs, with natural opium alkaloids (4.2\% of ADEs) the most common subgroup. While $52.8 \%$ of ADEs caused by natural opium alkaloids were mild, $16.7 \%$ were rated severe and $19.4 \%$ resulted in hospitalisation. These accounted for $14.3 \%$ of all hospitalisation for ADEs in this study. The recorded manifestations were those which would be clinically expected from this group of drugs.

ADEs from salicylates and non-steroidal antiinflammatory drugs (NSAIDs) were also relatively frequent causes of hospitalisation and together accounted for $12.2 \%$ of all hospitalisations for ADEs in this study.

When the relative prescribing and ADE rates were considered it was apparent that NSAIDs, antidepressants and bone mineralisation drugs had rates of ADEs that were significantly higher than the relative prescribing rates, while for drugs for peptic ulcer and gastro-oesophageal reflux disease (including proton pump inhibitors and histamine 2 receptor antagonists ), the ADE rate was significantly less than the relative prescribing rate.

\section{DISCUSSION}

More than 1 in 10 patients aged 45 and over presenting to a GP in Australia have experienced an ADE in the preceding 6 months, $54 \%$ being in the moderate to severe range of GP assessed severity and $5.4 \%$ being hospitalised as a result of the ADE.

This study is limited by the methodology of the SAND substudies of the BEACH programme, being constrained by the number of questions that could be asked and by the time that the GP could devote to clarifying the answers within the context of the consultation.

Patients attend general practice at variable rates related to age and morbidity. Therefore, some groups of patients are more likely to be included in these samples. As a result, the frequency of ADEs in patients attending GPs cannot be extrapolated to period prevalence of ADEs in the community.

The questions relied on patient/GP recall of events in the previous 6 months, so there may be some recall bias. 
Table 2 Relationship between drugs, prescribing rates, ADEs, severity of ADEs, and hospitalisation and manifestations of ADEs in patients aged 45 and over

\begin{tabular}{|c|c|c|c|c|c|c|c|c|c|c|c|}
\hline \multirow[b]{3}{*}{$\begin{array}{l}\text { Drug group } \\
\text { (ATC level 3) }\end{array}$} & \multirow[b]{3}{*}{$\begin{array}{l}\text { ATC } \\
\text { code }\end{array}$} & \multirow{3}{*}{$\begin{array}{l}\text { BEACH (2007- } \\
2010) \\
\text { Relative } \\
\text { prescribing } \\
\text { frequency, per } \\
\text { cent }(95 \% \mathrm{Cl} \text {; } \\
\mathrm{n}=170492) \\
\end{array}$} & \multicolumn{8}{|c|}{ SAND (all samples) } & \multirow{3}{*}{$\begin{array}{l}\text { SAND (2010 } \\
\text { samples only) } \\
\text { Manifestation of } \\
\text { most recent ADE } \\
\text { Main type/s of } \\
\text { reaction (ICPC-2 } \\
\text { rubrics) }\end{array}$} \\
\hline & & & \multirow[b]{2}{*}{$\begin{array}{l}\text { Relative ADE } \\
\text { frequency, per } \\
\text { cent }(95 \% \mathrm{Cl} \text {; } \\
\mathrm{n}=912)\end{array}$} & \multirow[b]{2}{*}{$\begin{array}{l}\text { Drug sub-group, } \\
\text { ATC level } 4 \text { or ATC } \\
\text { level } 3 \text { (ATC code) }\end{array}$} & \multirow[b]{2}{*}{$\begin{array}{l}\text { Relative ADE } \\
\text { frequency, per } \\
\text { cent }(95 \% \mathrm{Cl} \text {; } \\
\mathrm{n}=912)\end{array}$} & \multicolumn{3}{|c|}{ Severity of ADE } & \multicolumn{2}{|l|}{ Hospitalised } & \\
\hline & & & & & & $\begin{array}{l}\text { Mild, } \\
\text { percentage of } \\
\text { subgroup }\end{array}$ & $\begin{array}{l}\text { Moderate, } \\
\text { percentage of } \\
\text { subgroup }\end{array}$ & $\begin{array}{l}\text { Severe, } \\
\text { percentage of } \\
\text { subgroup }\end{array}$ & $\begin{array}{l}\text { Percentage } \\
\text { of sub-group }\end{array}$ & $\begin{array}{l}\text { Column, } \\
\text { per cent }\end{array}$ & \\
\hline Opioids & No2A & 6.5 (6.3 to 6.7$)$ & 8.2 (6.3 to 10.2$)$ & $\begin{array}{l}\text { Natural opium } \\
\text { alkaloids } \\
\text { (N02AA) }\end{array}$ & 4.2 (2.7 to 5.6$)$ & 52.8 & 30.6 & 16.7 & 19.4 & 14.3 & $\begin{array}{l}\text { Constipation, } \\
\text { vomiting, nausea, } \\
\text { vertigo/dizziness and } \\
\text { sleep disturbance }\end{array}$ \\
\hline Antidepressants & N06A & 4.3 (4.1 to 4.4 ) & 7.8 (6.0 to 9.6$)$ & $\begin{array}{l}\text { Selective serotonin } \\
\text { reuptake inhibitors } \\
\text { (N06AB) }\end{array}$ & $3.7(2.7$ to. 0$)$ & 47.1 & 41.2 & 11.8 & 3.1 & 2.0 & $\begin{array}{l}\text { Feeling anxious, } \\
\text { diarrhoea and } \\
\text { alpitations }\end{array}$ \\
\hline $\begin{array}{l}\text { Lipid-modifying agents, } \\
\text { plain }\end{array}$ & $\mathrm{C} 10 \mathrm{~A}$ & 6.1 (5.9 to 6.2 ) & 6.9 (5.0 to 8.8$)$ & $\begin{array}{l}\text { Statins } \\
\text { (C10AA) }\end{array}$ & 6.4 (4.5 to 8.2 ) & 36.2 & 48.3 & 15.5 & 3.4 & 0.0 & $\begin{array}{l}\text { Muscle pain, urticaria } \\
\text { and digestive } \\
\text { symptom NOS }\end{array}$ \\
\hline NSAIDs & M01A & 3.7 (3.6 to 3.9 ) & 6.3 (4.7 to 7.8 ) & $\begin{array}{l}\text { NSAIDs } \\
\text { (M01A) }\end{array}$ & 6.3 (4.7 to 7.8 ) & 45.6 & 45.6 & 8.8 & 10.5 & 8.1 & $\begin{array}{l}\text { Abdominal/epigastric } \\
\text { pain, nausea, rash } \\
\text { and swollen ankles/ } \\
\text { oedema }\end{array}$ \\
\hline ACE inhibitors, plain & C09A & 4.0 (3.9 to 4.1$)$ & 5.3 (3.7 to 6.8 ) & $\begin{array}{l}\text { ACE inhibitors-plain } \\
\text { (CO9AA) }\end{array}$ & 5.3 (3.7 to 6.8 ) & 64.6 & 31.3 & 4.2 & 0.0 & 0.0 & Cough \\
\hline Penicillins & J01C & 3.9 (3.7 to 4.0$)$ & 4.8 (3.4 to 6.3$)$ & $\begin{array}{l}\text { Penicillins } \\
\text { (J01C) }\end{array}$ & 4.8 (3.4 to 6.3 ) & 50.0 & 38.6 & 11.4 & 4.5 & 4.1 & $\begin{array}{l}\text { Diarrhoea, rash and } \\
\text { nausea }\end{array}$ \\
\hline $\begin{array}{l}\text { Selective calcium } \\
\text { channel blockers with } \\
\text { mainly vascular effects }\end{array}$ & $\mathrm{C} 08 \mathrm{C}$ & 2.6 (2.5 to 2.7$)$ & 3.9 (2.7 to 5.2$)$ & $\begin{array}{l}\text { Calcium channel } \\
\text { blockers (CO8C) }\end{array}$ & 3.9 (2.7 to 5.2$)$ & 55.6 & 30.6 & 13.9 & 0.0 & 0.0 & $\begin{array}{l}\text { Swollen ankles/ } \\
\text { oedema and rash }\end{array}$ \\
\hline \multirow[t]{2}{*}{ Other analgesics N02B } & & 3.3 (3.2 to 3.4 ) & 3.9 (2.7 to 5.2 ) & Salicylates (N02BA) & 1.4 (0.7 to 2.2$)$ & 46.2 & 38.5 & 15.4 & 16.7 & 4.1 & $\begin{array}{l}\text { Cardiac arrhythmia, } \\
\text { malaena, haematuria } \\
\text { and haemoptysis }\end{array}$ \\
\hline & & & & Anilides (N02BE) & 2.5 (1.4 to 3.6$)$ & 52.2 & 39.1 & 8.7 & 0.0 & & Tinnitus \\
\hline$\beta$ blocking agents & C07A & 2.9 (2.8 to 3.0$)$ & 2.6 (1.6 to 3.6 ) & $\begin{array}{l}\beta \text { blocking agents } \\
(\text { CO7A) }\end{array}$ & 2.6 (1.6 to 3.6 ) & 29.2 & 66.7 & 4.2 & 0.0 & 0.0 & $\begin{array}{l}\text { Cardiac arrhythmia, } \\
\text { nausea, weakness/ } \\
\text { tiredness and } \\
\text { postural hypotension }\end{array}$ \\
\hline $\begin{array}{l}\text { Hypoglycaemic agents } \\
\text { excluding insulins }\end{array}$ & $A 10 B$ & 3.4 (3.3 to 3.5 ) & 2.6 (1.5 to 3.7 ) & Biguanides (A10BA) & 1.5 (0.7 to 2.3$)$ & 14.3 & 71.4 & 14.3 & 7.1 & 2.0 & $\begin{array}{l}\text { Diarrhoea and } \\
\text { nausea }\end{array}$ \\
\hline $\begin{array}{l}\text { Drugs for bone structure } \\
\text { and mineralisation }\end{array}$ & M05B & 0.9 (0.9 to 1.0$)$ & 2.3 (1.3 to 3.3 ) & $\begin{array}{l}\text { Bisphosphonates } \\
\text { (M05BA/BB) }\end{array}$ & 1.5 (0.7 to 2.3 ) & 38.9 & 38.9 & 22.2 & 0.0 & 0.0 & $\begin{array}{l}\text { Fever, nausea and } \\
\text { pain }\end{array}$ \\
\hline $\begin{array}{l}\text { Drugs for peptic ulcer } \\
\text { and gastro-oesophageal } \\
\text { reflux disease }\end{array}$ & A02B & 4.4 (4.3 to 4.5$)$ & $2.2(1.2$ to 3.1$)$ & $\begin{array}{l}\text { Proton pump } \\
\text { inhibitors (A02BC) }\end{array}$ & $2.0(1.1$ to 2.9$)$ & 38.9 & 44.4 & 16.7 & 6.3 & 2.0 & $\begin{array}{l}\text { Diarrhoea and } \\
\text { abdominal pain }\end{array}$ \\
\hline Antiepileptics & N03A & 0.8 (0.7 to 0.8$)$ & 1.8 (0.8 to 2.7$)$ & Antiepileptics (NO3A) & 1.8 (0.8 to 2.7$)$ & 56.3 & 31.3 & 12.5 & 6.3 & 2.0 & $\begin{array}{l}\text { Neurological } \\
\text { symptom NOS, sleep } \\
\text { disorder and speech } \\
\text { disorder }\end{array}$ \\
\hline
\end{tabular}

ADE, adverse drug events; ATC, Anatomical Therapeutic Chemical; BEACH, Bettering the Evaluation And Care of Health; ICPC-2, International Classification of Primary Care Version 2;

NOS, not otherwise specified; NSAIDs, Non-Steroidal Anti-Inflammatory Agents; SAND, Supplementary Analysis of Nominated Data. 
The study must therefore be regarded as a quantification of ADEs from the perspective of the GP and the patient. The GP was therefore the judge of appropriateness of indication and dosage of drugs causing ADEs and this may introduce a bias against reporting inappropriate indication or dose. However, the overall consistency of the results over five collection periods by different groups of about 100 GPs suggests a common interpretation of causality and severity.

A major strength of this study is that it contains data from a large sample of patients collected by hundreds of randomly selected GPs representing 2.7\% of all the practising GPs in Australia. GPs in the BEACH programme are nationally representative of all the GPs practising in Australia. ${ }^{22}$ The GPs use their medical records, knowledge of the patient and their clinical skills and experience to interpret the reported ADEs. In the SAND substudies they act as expert clinical interviewers.

Research on under-reporting of serious ADEs in the $\mathrm{USA}^{23-25}$ and Canada, ${ }^{26-28}$ suggests that formal reporting rates may represent as little as $1.5 \%$ of total ADEs. USA estimates place the mortality from ADEs as the fifth most common cause of death after heart disease, cancer, stroke and pulmonary disease. ${ }^{25}$ The level of morbidity revealed in this study must place ADEs as one of the most important causes of morbidity in the Australian community. The most severe result of ADEs, namely death, was of course not included, as this was a study of patients attending a GP. While the very severe ADEs may occur and be managed in the acute care sector, a large number of mild and moderate ADEs and many of the severe reactions must be managed in the community.

While the vast majority of studies in the literature concentrate on prescribing 'errors' and 'preventable' ADEs, this study and our previous research demonstrates that the large majority of ADEs occurring in primary medical care in Australia fall into the WHO category of adverse drug reactions (ADRs), ${ }^{29}$ occurring in patients on appropriate dosages of medication, prescribed for appropriate indications. This group of ADEs are frequently ignored as the 'price we pay' for effective management of disease. However, there is further evidence from this study that for many patients the price may be too high.

The list of drugs implicated in this study as associated with ADEs bears little relationship to lists of 'IMs' such as that developed by Beers et al. A large number of 'appropriate medications' are implicated as causing ADEs. Gandhi et $a l^{30}$ in a prospective study of ADEs in primary care in Boston, also found that ADEs are frequently caused by similar commonly used groups of drugs. Budnitz et al, ${ }^{31}$ studying emergency hospitalisations for ADEs, also concluded "most emergency hospitalisations for recognised ADEs in older adults resulted from a few commonly used medications, and relatively few resulted from medications typically designated as high risk or inappropriate." Laroche $e t$ al also found that ADEs in elderly patients (70 years and older) were rarely caused by IMs. ${ }^{4}$ Many of the drug groups implicated as causes of ADEs in this study are used for the prevention of cardiovascular disease. These drugs may have little perceived immediate benefit in the eyes of the patients while inducing significant morbidity from ADEs.

Considering the wide range of drugs that cause significant reactions at therapeutic dosage levels, constant vigilance is required by clinicians to minimise the risk of ADEs. Reducing the number of drugs taken by older patients is paramount in efforts to reduce ADRs. Inclusion of information about the frequency and severity of ADEs in prescribing decision support systems may assist GPs to weigh the risk/benefit of commonly used medications in older patients.

Acknowledgements The authors would like to thank the GPs who participated, and the Primary and Ambulatory Care Division of the Australian Government Department of Health and Ageing for supply of the BEACH GP sample frame data.

Contributors All authors contributed to the conception and design, interpretation of data, drafting and critical revision of important intellectual content. All authors had full access to all the data. LV performed the statistical analysis. GCM wrote the first draft of the article and all authors approved the final version. GCM is the study guarantor.

Funding Between 2006 and 2010 the BEACH programme, of which this substudy is a part, was funded by the Australian Government Department of Health and Ageing, the Australian Government Department of Veterans' Affairs, Australian Institute of Health and Welfare, National Prescribing Service, AstraZeneca Pty Ltd (Australia), Janssen-Cilag Pty Ltd, Merck, Sharpe and Dohme (Australia) Pty Ltd, Pfizer Australia Pty Ltd, Abbott Australasia Pty Ltd, Sanofi-Aventis Australia Pty Ltd, Novartis Pharmaceuticals Australia Pty Ltd, GlaxoSmithKline Australia Pty Ltd, Bayer Australia Ltd. The SAND substudy reported in this paper was commissioned by the Family Medicine Research Centre.

Competing interests None.

Ethics approval The BEACH programme and this substudy were approved by the Human Research Ethics Committee of the University of Sydney (Reference No. 7185) and the Ethics Committee of the Australian Institute of Health and Welfare.

Provenance and peer review Not commissioned; externally peer reviewed.

Data sharing statement No additional data are available.

Open Access This is an Open Access article distributed in accordance with the Creative Commons Attribution Non Commercial (CC BY-NC 3.0) license, which permits others to distribute, remix, adapt, build upon this work noncommercially, and license their derivative works on different terms, provided the original work is properly cited and the use is non-commercial. See: http:// creativecommons.org/licenses/by-nc/3.0/

\section{REFERENCES}

1. Australian Government Department of Health and Ageing. Medicare Statistics-March quarter 2011, Group BC tables. Canberra: DOHA. http://www.health.gov.au/internet/main/publishing.nsf/Content/ medstat-mar11-tables-bc (accessed Sep 2011).

2. Britt $\mathrm{HC}$, Harrison CM, Miller GC, et al. Prevalence and patterns of multimorbidity in Australia. Med J Aust 2008;189:72-7.

3. Caughey GE, Vitry Al, Gilbert AL, et al. Prevalence of comorbidity of chronic diseases in Australia. BMC Public Health 2008;8:221.

4. Laroche ML, Charmes JP, Nouaille Y, et al. Is inappropriate medication use a major cause of adverse drug reactions in the elderly? Br J Clin Pharmacol 2007;63:177-86.

5. Calderon-Larranaga A, Poblador-Plou B, Gonzalez-Rubio F, et al. Multimorbidity, polypharmacy, referrals, and adverse drug events: are we doing things well? Br J Gen Pract 2012;62:e821-6.

6. Bourgeois FT, Shannon MW, Valim C, et al. Adverse drug events in the outpatient setting: an 11-year national analysis. Pharmacoepidemiol Drug Saf 2010;19:901-10. 
7. Sarkar U, Lopez A, Maselli JH, et al. Adverse drug events in US adult ambulatory medical care. Health Serv Res 2011;46:1517-33.

8. Miller GC, Britt HC, Valenti L. Adverse drug events in general practice patients in Australia. Med J Aust 2006;184:321-4.

9. Tache SV, Sonnichsen A, Ashcroft DM. Prevalence of adverse drug events in ambulatory care: a systematic review. Ann Pharmacother 2011;45:977-89.

10. Beers $\mathrm{MH}$, Ouslander JG, Rollingher I, et al. Explicit criteria for determining inappropriate medication use in nursing home residents. UCLA Division of Geriatric Medicine. Arch Intern Med 1991;151:1825-32.

11. Beers $\mathrm{MH}$. Explicit criteria for determining potentially inappropriate medication use by the elderly. An update. Arch Intern Med 1997;157:1531-6.

12. Fick DM, Cooper JW, Wade WE, et al. Updating the Beers criteria for potentially inappropriate medication use in older adults: results of a US consensus panel of experts. Arch Intern Med 2003;163:2716-24.

13. Britt H, Miller GC, Charles J, et al. General practice activity in Australia 2008-09. Canberra: Australian Institute of Health and Welfare, 2009. (AIHW Cat. No. GEP 25;) (General Practice Series No. 25). http://www.aihw.gov.au/publications/index.cfm/title/ 11013

14. Britt H, Miller GC, Henderson J, et al. General practice activity in Australia 2011-12. Sydney: Sydney University Press, 2012. (General practice series no. 31). http://purl.library.usyd.edu.au/sup/ 9781743320181

15. AlHW Australian GP Statistics and Classification Centre. SAND Method: 2009-10. SAND abstracts from the BEACH program. [serial on the Internet]. Sydney: The University of Sydney. http://nla.gov.au/ nla.arc-14007 (accessed Feb 2012).

16. Driver B, Britt H, O'Toole B, et al. How representative are patients in general practice morbidity surveys? Fam Pract 1991;8:261-8.

17. Britt $\mathrm{H}$, Harris $\mathrm{M}$, Driver $\mathrm{B}$, et al. Reasons for encounter and diagnosed health problems: convergence between doctors and patients. Fam Pract 1992;9:191-4.
18. Britt $\mathrm{H}$, Miller GC, Steven ID, et al. Collecting data on potentially harmful events: a method for monitoring incidents in general practice. Fam Pract 1997;14:101-6.

19. World Health Organization Collaborating Centre for Drug Statistics Methodology. Anatomical Therapeutic Chemical (ATC) classification index with Defined Daily Doses (DDDs). January 2009 ed. Oslo: WHO; 2009. http://www.whocc.no/

20. Classification Committee of the World Organization of Family Doctors. ICPC-2: international classification of primary care. 2nd edn. Oxford: Oxford University Press, 1998.

21. SAS Proprietary Software Release 9.1. Cary: SAS Institute Inc, 2003.

22. Britt H, Miller GC, Charles J, et al. General practice activity in Australia 2006-07. Canberra: Australian Institute of Health and Welfare, 2008. (AlHW Cat. No. GEP 21); (General practice series no. 21). http://www.aihw.gov.au/publications/index.cfm/title/10574

23. Fischer G, Fetters MD, Munro AP, et al. Adverse events in primary care identified from a risk-management database. J Fam Pract 1997;45:40-6.

24. Moore TJ, Psaty BM, Furberg CD. Time to act on drug safety. JAMA 1998;279:1571-3.

25. Motl S, Timpe E, Eichner S. Proposal to improve MedWatch: decentralized, regional surveillance of adverse drug reactions. $A m \mathrm{~J}$ Health Syst Pharm 2004;61:1840-2.

26. Bains $\mathrm{N}$, Hunter D. Adverse reporting on adverse reactions. CMAJ 1999;160:350-1.

27. Lexchin J. Adverse drug reactions: review of the Canadian literature. Can Fam Physician 1991;37:109-18.

28. Lexchin J. Rethinking the numbers on adverse drug reactions. CMAJ 1999;160:1432.

29. World Health Organization. Medicines: safety of medicines-adverse drug reactions. Fact sheet no. 283. Geneva: WHO, http://www.who. int/mediacentre/factsheets/fs293/en/ (accessed Mar 2013).

30. Gandhi TK, Weingart SN, Borus J, et al. Adverse drug events in ambulatory care. N Engl J Med 2003;348:1556-64.

31. Budnitz DS, Lovegrove MC, Shehab N, et al. Emergency hospitalizations for adverse drug events in older Americans. $N$ Engl J Med 2011;365:2002-12. 